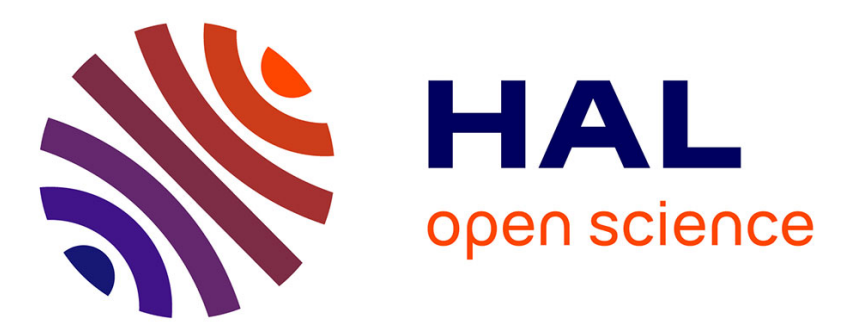

\title{
Numerical study on the effect of the paint layer used for infrared thermography on heat source estimation
}

\author{
Vincent Delobelle, Hervé Louche, D Favier
}

\section{To cite this version:}

Vincent Delobelle, Hervé Louche, D Favier. Numerical study on the effect of the paint layer used for infrared thermography on heat source estimation. Quantitative InfraRed Thermography Journal, 2014, 11 (2), pp.233-249. 10.1080/17686733.2014.971618 . hal-01280470

\section{HAL Id: hal-01280470 \\ https://hal.science/hal-01280470}

Submitted on 29 Feb 2016

HAL is a multi-disciplinary open access archive for the deposit and dissemination of scientific research documents, whether they are published or not. The documents may come from teaching and research institutions in France or abroad, or from public or private research centers.
L'archive ouverte pluridisciplinaire HAL, est destinée au dépôt et à la diffusion de documents scientifiques de niveau recherche, publiés ou non, émanant des établissements d'enseignement et de recherche français ou étrangers, des laboratoires publics ou privés. 


\title{
Numerical study on the effect of the paint layer used for infrared thermography on heat source estimation.
}

\author{
V. Delobelle ${ }^{a}$ and H Louche ${ }^{b *}$ and D. Favier ${ }^{a}$ \\ ${ }^{a}$ Université de Grenoble/CNRS, TIMC-IMAG UMR 5525, Grenoble, France; \\ ${ }^{b}$ Laboratoire de Mécanique et Génie Civil (LMGC),Université de Montpellier 2, CNRS, \\ CC048, place E. Bataillon, 34095 Montpellier Cedex,France
}

\begin{abstract}
This paper investigates the effect of the paint layer used for infrared thermography on the heat source estimation for thin plates. The thermal behaviour of two plates is studied using finite element modelling. The first one is composed of the studied homogeneous material. The second one is a sandwich plate composed of a central material covered on each side with a high emissivity paint layer. For the two plates, two thermal loading cases are simulated. Case 1 corresponds to natural cooling from a initial uniform temperature to room temperature. Case 2 corresponds to a situation where the initial uniform temperature is equal to room temperature. In both cases, the central material is loaded with internal heat sources leading to temperature field variation. From the computed external surface temperature, heat sources and energy are then estimated using homogeneous plate and sandwich plate models derived from the heat diffusion equation. Then, the estimated heat sources are compared to the one input in the finite element model. It is shown that the paint layer significantly isolates the central material from the external environment. In case 1, it is shown that the error is reduced from $10 \%$ with the homogeneous plate model to $5 \%$, with the sandwich plate model. In case
\end{abstract}

*Corresponding author. Email: herve.louche@univ-montp2.fr 
2, heat sources are estimated with an error of less than $8 \%$ with the homogeneous plate model while it is below $2 \%$ with the sandwich plate model. The sandwich plate model is thus significantly more accurate for heat source and energy estimations than the homogeneous plate model.

Keywords: heat sources estimation; numerical benchmark; paint layer; infrared thermography

\section{Introduction}

2. Theoretical Framework

2.1. Heat diffusion model

2.2. Simplified models for homogeneous material in the thickness direction

2.3. Simplified models for heterogeneous material in the thickness direction 3. Numerical benchmark

3.1. Finite element model description

3.1.1. Plane geometries

3.1.2. Boundary conditions

3.1.3. Initial states and loading

3.2. Heat source estimation: application

to the simulation data

3.2.1. Flowchart

3.2.2. Case 1 results

3.2.3. Case 2 results

4. General Discussion

5. Conclusion

6. Appendix 


\section{Introduction}

Temperature field measurements are interesting tools to study thermomechanical couplings often associated with the deformation of materials. However, their interpretation is difficult. An approach, based on the determination of heat sources, causes of temperature variations, can be used. However, internal heat sources are not directly measured and their estimation is still an open issue. Many techniques have been proposed to get such heat source values [1-4]. Due to the ill-posed nature of this problem, some regularization operations have to be applied to the temperature data. The direct method proposed in [1] is based on approximations of temporal and spatial derivative operators involved in the heat diffusion equation. Raw and noisy thermal fields, measured by an infrared camera, are temporally and spatially filtered before applying the different derivative operators involved in the heat diffusion equation. Such a method has been applied to study Lüders bands and necking in steels $[1,5]$, PLC bands in AlMg alloys [6], fatigue of materials [710], plasticity in Al olygocrystals [11], plasticity in steels [12] and stress induced phase transformation in shape memory alloys (SMA) [13, 14].

The accuracy of these heat source estimations is also an open question. Errors in heat source estimations can be due to: (i) errors in thermal field measurements, (ii) errors in the thermal model, (iii) errors in the thermophysical parameters involved in the thermal model and (iv) errors in the signal processing operations. Validation procedures for heat source field estimation methods are then necessary.

Two kinds of validation procedure may be applied. The first one, qualified as "numerical", was used in 2D Cartesian [1] and 2D cylindrical [13] coordinate systems. It is based on associated temperature and heat source fields computed analytically or numerically. The second one, qualified as "experimental" refers to real problems where temperature and heat sources are quantitatively known. $[15,20]$ proposed a first experimental vali- 
dation based on the observation of the austenite to $\mathrm{R}$ phase transformation occurring in NiTi SMA.

The temperature uniformity in the thickness of the studied specimen is the main hypothesis used to formulate models proposed in [1]. The studied samples are often thin plates with a thickness of 0.3 to $3 \mathrm{~mm}[6,8,13,15]$. Their surfaces are coated with paint layers to enhance emissivity which is supposed to be uniform. The layer thickness is $\approx 25 \pm 5 \mu \mathrm{m}$. Thus, for thinner plates, it represents approximately $20 \%$ of the total sample thickness. Moreover, these paint layers have poor thermal conductivity in comparison to metals, i.e. about $0.2 \mathrm{Wm}^{-1} \mathrm{~K}^{-1}$ [16-18]. Although [16] investigated the effect of the paint on the temperature distribution in sandwich sample and $[1,13,15]$ validated the heat source estimation, no studies have focused on the impact of the paint layer used to get quantitative thermal field measurements on heat source estimations. Generally, in experimental studies, this paint layer is not taken into account in heat source estimation.

This paper investigates the effect of neglecting or taking into account the paint layer on heat source estimation. A "numerical" validation of heat source estimation from thermal fields computed with the FEM method is proposed. The errors due to the paint layer on the temperature measured and on the heat source estimation in regard of the thermal model used are studied. This paper does not investigates signal processing because it was already done in [13] and because the paint layer has no effect on that numerical source of error. Error due to uncertainty of the thermophysical properties will be studied in an other study. In the case 1, the natural cooling proposed in [15] is simulated and investigates the influence of the paint layer on heat source estimations. In the case 2 , temperature variation only due to internal heat sources is simulated, as observed during mechanical loading of NiTi SMA, for example [19], and investigates the influence of the paint layer on heat source estimations. Firstly, the theoretical framework is explained in Section 2. The numerical benchmark and results are proposed in Section 3. The results 
are finally discussed in Section 4.

\section{Theoretical framework - Heat source estimation models}

\section{$2.1 \quad$ Heat diffusion models}

In this part, the simplified thermal equations used to estimate heat sources are presented. The mathematical formulations are fully explained in $[1,13]$. The starting general 3D heat diffusion equation linking temperature $T(x, y, z, t)$ and heat sources $s(x, y, z, t)$ at a spatial point located in $(x, y, z)$ in a spatial coordinate system $(\vec{x}, \vec{y}, \vec{z})$ defined in Fig. 1, at current time $t$ is expressed in the following form:

$$
\rho C \frac{\partial T}{\partial t}-k \operatorname{lap}(T)=s=s_{\text {internal }}+s_{\text {external }}
$$

where $\rho$ is the volumic mass, $C$ the heat capacity, $k$ the thermal conductivity of the material and lap the laplacian operator. On the right hand side of this equation, $s_{\text {internal }}$ and $s_{\text {external }}$ are respectively the internal and external volumic heat sources $\left(W m^{-3}\right)$. This equation is valid assuming an homogeneous and isotropic thermal material behaviour. The convective part of the time derivative of $T$ is also neglected. Other hypotheses are considered here after: (i) a sample geometry corresponding to $L>l \gg e$ where $L, l$ and $e$ are length, width and thickness of the rectangular plate, respectively, in the direction $\vec{x}$,

$\vec{y}, \vec{z}$, (ii) the temperature is almost uniform in the thickness direction. In this paper, the average value of function $\xi$ in the thickness direction $\vec{z}$ is noted:

$$
\widetilde{\xi}=\widetilde{\xi}(x, y, t)=\frac{1}{e} \int_{-e / 2}^{e / 2} \xi(x, y, z, t) d z
$$

Then the average value of function $\xi$ in the thickness and width directions $(\vec{z}$ and $\vec{y})$ 
is noted:

$$
\widetilde{\widetilde{\xi}}=\widetilde{\widetilde{\xi}}(x, t)=\frac{1}{l} \int_{-l / 2}^{l / 2} \widetilde{\xi}(x, y, t) d y
$$

Finally, the average value of function $\xi$ in the thickness, width and length directions $(\vec{z}, \vec{y}$ and $\vec{x})$ is noted:

$$
\widetilde{\widetilde{\xi}}=\widetilde{\widetilde{\xi}}(t)=\frac{1}{L} \int_{-L / 2}^{L / 2} \widetilde{\widetilde{\xi}}(x, t) d x,
$$

Then, from general heat diffusion equation (1), simplified models for an homogeneous plate and for a sandwich plate in the thickness are established.

\subsection{Simplified models for homogeneous plates in the thickness direction}

Equation (1) is integrated in the $\vec{z}$ direction in order to obtain its 2D expression. From the previous hypotheses and using the appropriate mathematical formulation $[1,13]$, the 2D heat equation can be written as:

$$
\rho C \frac{\partial \widetilde{T}}{\partial t}+\frac{2 h}{e}\left(\widetilde{T}-T_{0}\right)+\frac{2 \epsilon \sigma}{e}\left(\widetilde{T}^{4}-T_{0}^{4}\right)-k \operatorname{lap}_{2 D}(\widetilde{T})=\widetilde{s}=\rho \tilde{\dot{q}}
$$

where $T_{0}$ is the environment temperature, $\sigma$ the Stephan-Boltzmann constant and $\epsilon$ the emissivity. $h$ is the convection coefficient applied to the back and front sides of the sample. $\operatorname{lap}_{2 D}$ is the 2 D Laplacian operator in a Cartesian coordinate system $: \operatorname{lap}_{2 D}(\widetilde{T})=$ $\frac{\partial^{2} \widetilde{T}}{\partial x^{2}}+\frac{\partial^{2} \widetilde{T}}{\partial y^{2}}$. On the right hand side of equation (5), $\widetilde{\dot{q}}$ are the mean massic heat sources $\left(W \mathrm{~kg}^{-1}\right)$ in the thickness direction. Then, equation (5) is integrated in the transverse direction $\vec{y}$ to establish the 1D homogeneous plate model: 


$$
\rho C \frac{\partial \widetilde{\widetilde{T}}}{\partial t}+\frac{2 h}{e}\left(\widetilde{\widetilde{T}}-T_{0}\right)+2 \epsilon \sigma\left(\frac{1}{e}+\frac{1}{l}\right)\left(\widetilde{\widetilde{T^{4}}}-T_{0}^{4}\right)-k \operatorname{lap}_{1 D}(\widetilde{\widetilde{T}})=\widetilde{\widetilde{s}}=\rho \tilde{\dot{q}}
$$

where $l a p_{1 D}$ is the 1 D Laplacian operator in a Cartesian coordinate system: $\operatorname{lap}_{1 D}(\widetilde{\widetilde{T}})=$ $\frac{\partial^{2} \widetilde{\widetilde{T}}}{\partial x^{2}}$.

Finally, integration of equation (6) in the axial direction leads to the 0D homogeneous plate model:

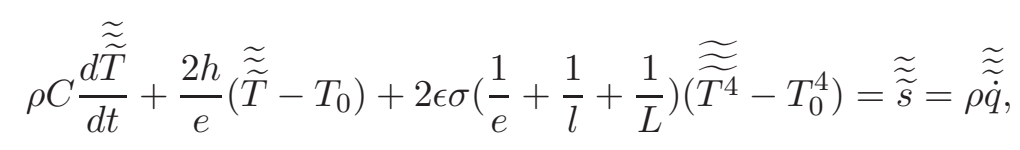

In equations (6) and (7), due to the sample geometry, the following approximations are proposed: $\frac{1}{e}+\frac{1}{l} \approx \frac{1}{e}$ and $\frac{1}{e}+\frac{1}{l}+\frac{1}{L} \approx \frac{1}{e}$.

\subsection{Simplified models for sandwich plates in the thickness direction}

A paint with a high emissivity coefficient is used to coat samples for the purpose of quantitative temperature measurement with an infrared camera. Thus, the real material studied is a sandwich plate of width $l$ and length $L$, composed of a homogeneous central material (2) and two identical layers (1 and 3) on both sides of the sample (Fig. 1). The thickness, volumic mass, thermal conductivity, specific heat, volumic heat sources, specific heat sources and temperature are denoted $e_{i}, \rho_{i}, k_{i}, C_{i}, s_{i}, q_{i}$ and $T_{i}$ for $i=1,2,3$, respectively. The two paint layers have identical properties $\left(e_{1}=e_{3}, \rho_{1}=\rho_{3}, \ldots\right)$ and it is assumed that there are no heat sources in the layers $\left(s_{1}=s_{3}=0\right)$.

Thus, with the hypotheses and the development described in the Appendix, it is possible to develop the complete $2 \mathrm{D}$ thermal model for this sandwich plate: 
$\frac{2 e_{1} \rho_{1} C_{1}+e_{2} \rho_{2} C_{2}}{e_{2}} \frac{\partial \widetilde{T}}{\partial t}-\frac{2 e_{1} k_{1}+e_{2} k_{2}}{e_{2}} \operatorname{lap}_{2 D}(\widetilde{T})+\frac{2 \epsilon \sigma}{e_{2}}\left(\widetilde{T^{4}}-T_{0}^{4}\right)+\frac{2 h}{e_{2}}\left(\widetilde{T}-T_{0}\right)=\widetilde{s_{2}}=\rho_{2} \widetilde{q_{2}}$.

Then, this equation is integrated in the transverse direction of the sample to formulate the 1D sandwich plate model:

$\left.\frac{2 e_{1} \rho_{1} C_{1}+e_{2} \rho_{2} C_{2}}{e_{2}} \frac{\partial \widetilde{\widetilde{T}}}{\partial t}-\frac{2 e_{1} k_{1}+e_{2} k_{2}}{e_{2}} \operatorname{lap}_{1 D}(\widetilde{\widetilde{T}})+\frac{2 \epsilon \sigma}{e_{2}}\left(\widetilde{\widetilde{T^{4}}}-T_{0}^{4}\right)+2 h\left(\frac{1}{e_{2}}+\frac{1}{l}\right)\left(\widetilde{\widetilde{T}}-T_{0}\right)\right)=\widetilde{\widetilde{s_{2}}}=\rho_{2} \widetilde{\widetilde{q_{2}}}$

and integration in the axial direction leads to the 0D sandwich plate model:

$$
\left.\frac{2 e_{1} \rho_{1} C_{1}+e_{2} \rho_{2} C_{2}}{e_{2}} \frac{\partial \widetilde{\widetilde{T}}}{\partial t}+\frac{2 \epsilon \sigma}{e_{2}}\left(\underset{\widetilde{T^{4}}}{\approx}-T_{0}^{4}\right)+2 h\left(\frac{1}{e_{2}}+\frac{1}{l}+\frac{1}{L}\right)\left(\widetilde{\widetilde{T}}-T_{0}\right)\right)=\underset{\widetilde{s_{2}}}{\approx}=\rho_{2} \underset{\widetilde{\dot{q}_{2}}}{\approx},
$$

in which the terms $\frac{1}{e_{2}}+\frac{1}{l} \approx \frac{1}{e_{2}}$ and $\frac{1}{e_{2}}+\frac{1}{l}+\frac{1}{L} \approx \frac{1}{e_{2}}$.

\section{Numerical benchmark}

The following numerical benchmark will focus on the validation and comparison of the proposed 0D models. The model presented in equation (7) is called a homogeneous plate model. The model presented in equation (10) is called a sandwich plate model.

\subsection{Finite element model description}

\subsubsection{Geometries and mesh}

In this study, two different line geometries were meshed with 1D thermal elements in the thickness direction of the sample presented in Fig. 1. Due to the symmetry of the sample in this direction, half symmetry condition is considered in the center of the sample in the following FEM models. The first one presented in Fig. 2.a was only composed of 
the central material $(c)$, of thickness $\left(e_{c} / 2\right)$ equal to $0.25 \mathrm{~mm}$. The second geometry, shown in Fig. 2.b, was composed of the central material $(c)$, of thickness $\left(e_{c} / 2\right)$ equal to $0.25 \mathrm{~mm}$ in which a paint layers $(P)$ with a thickness $e_{P}=0.03 \mathrm{~mm}$ was added on the sample side. In the considered FEM models, $(c)$ was meshed with 5 linear elements in the thickness direction and $(P)$ was meshed with 10 linear elements in the thickness direction. Such a mesh allows to describe accurately the temperature variation and gradient in the thickness of the core material and of the paint, as shown in [23]. With these two geometries, it is possible to evaluate the influence of the paint on a $0 \mathrm{D}$ thermal response, and then on the heat source estimation.

\subsubsection{Boundary conditions}

Thermophysical properties of material $(c)$ and $(P)$ are given in Table 1. The central material has titanium properties. In the second FEM model (Fig. 2.b), a quasi infinite conductance of the interfaces between materials is used to model the contact between the central material $(c)$ and the paint $(P)$. The room temperature is $T_{0}=20^{\circ} \mathrm{C}$. Heat exchanges are convection, with a coefficient $h=50 \mathrm{Wm}^{-2} \mathrm{~K}^{-1}$ (lightly forced) and radiation, with an emissivity of $\epsilon=0.95$ on the external point noted $z_{+}$in Fig. 2. Heat exchanges are considered null in the $x$ direction.

Table 1. Thermophysical properties of Titanium [21] and paint [16-18].

\begin{tabular}{lccc}
\hline Material & Volumic mass & Specific heat & Thermal Conductivity \\
& $\rho\left(k g \mathrm{~m}^{-3}\right)$ & $C\left(\mathrm{~kg}^{-1} \mathrm{~K}^{-1}\right)$ & $k\left(W \mathrm{~m}^{-1} K^{-1}\right)$ \\
\hline & & & 21 \\
\hline Titanium $(c)$ & 4510 & 540 & 0.2 \\
\hline & & & \\
\hline
\end{tabular}




\subsubsection{Initial states and loading}

In the initial state, the whole sample $((c)$ and $(P))$ is at a uniform and constant temperature $T_{i n i}$. Uniform heat sources $s_{F E M}$ inside the central plate are applied to the two geometries shown in Figs. 2.a and b. For the two geometries, two cases were studied in regard to the experimental behaviour observed in NiTi SMAs.

- Case 1: the values $T_{i n i}^{1}=100^{\circ} C$ and $s_{F E M}^{1}$ plotted in Fig. 3.a were chosen. This case is similar to the exothermic heat source that occurs during a thermal induced phase transformation, as in the experimental benchmarks proposed in $[15,20]$. In $[15,20]$, the NiTi SMA cools from a high temperature where the material is in Austenite phase (A), to a low temperature where the material is in Martensite phase (M). In NiTi SMA, a latent heat of transformation is associated with the A-M phase change. Thus, during cooling, the A-M phase change occurs and acts as internal heat source.

- Case 2: $T_{i n i}^{2}=T_{0}=20^{\circ} \mathrm{C}$ and $s_{F E M}^{2}$ plotted in Fig. 3.b were chosen. This case is similar to the exothermic heat source that occurs during stress induced phase transformation when loading (e.g. in tension) SMA sample [13, 22]. In [13, 22], the sample is initially at room temperature. If the material is initially in the A phase, during loading the A-M phase change occurs, thus conferring to the material its famous superelastic properties. As in the first case, a latent heat of transformation is associated with the phase change and acts as an internal heat source.

\subsection{Heat source estimation: application to simulation data}

\subsubsection{Flowchart}

The flowchart shown in Fig. 4 illustrates the method used to study the influence of the paint layer on the accuracy of the heat source estimation. An identical flowchart is used 
for the two previously presented cases.

Imposed internal heat sources $s_{F E M}$ are applied to the plate without paint (WP, Fig. 2.a) and to the plate with paint layers (PL), see Fig. 2.b. In the case without paint, the computed external temperature is denoted $T_{W P}$. When the sample is painted, the temperature computed at the external and internal surfaces of the paint layer are denoted $T_{P \text { Lext }}$ and $T_{P \text { Lint }}$, respectively, and then the difference $\Delta T_{P L}=T_{P \text { Lext }}-T_{P \text { Lint }}$ is calculated. The influence of the paint on the measured temperature is characterized by the external temperature difference $\Delta T=T_{W P}-T_{P \text { Lext }}$.

The simulated external temperature data $T_{W P}$ and $T_{P \text { Lext }}$ are then post processed using heat source models neglecting (homogeneous plate model: equation 7) or taking into account (sandwich plate model: equation 10) the effect of the paint layers. The external surface temperature from the sample without paint $T_{W P}$ is processed with equation (7) in order to obtain the heat source denoted $s_{W P}$. With paint, thermal data at the external surfaces $T_{P \text { Lext }}$ is processed with equations (7) and (10), in order to estimate the heat sources $s_{\text {PLext }}$ and $s_{\text {PLext }}^{e q}$, respectively.

The approximations of the operators located on the left hand side members of equations $(7)$ and $(10)$ are explained in $[1,13]$. Spatio-temporal filtering operations are necessary since the experimental thermal data are noisy. Filtering process was studied in [13] in noisy data. In the present paper, temperature fields are homogeneous and the data are only filtered in time. Moreover, these fields obtained numerically are noisy free, compared to experimental data which are typically affected by a random noise (thermal resolution: NETD of $20 \mathrm{mK}$ ). In order to compare this numerical study with an experimental one, the same parameters for the low-pass temporal filtering as in the experimental case was kept, i.e. filtering order of 10 and a low pass cut-off frequency of $1 \%$ of the Nyquist frequency. The filtering process parameters are identical in the two studied cases.

Then the differences between the reference heat source used in the FEM model $\left(s_{F E M}\right)$ 
and $s_{W P}, s_{P L e x t}, s_{P L e x t}^{e q}$ are calculated and denoted $\Delta s_{W P}=s_{W P}-s_{F E M}, \Delta s_{P L e x t}=$ $s_{P \text { Lext }}-s_{F E M}$ and $\Delta s_{P \text { Lext }}^{e q}=s_{P L e x t}^{e q}-s_{F E M}$, respectively.

The energy (denoted $E$ ), associated with the different heat sources is calculated through the following temporal integration:

$$
E=\int_{0}^{t} s(t) d t
$$

The energy imposed in the FEM model is denoted $E_{F E M}=\int_{0}^{t} s_{F E M}(t) d t$. Then the energy estimated from the simulation without paint is denoted $E_{W P}=\int_{0}^{t} s_{W P}(t) d t$. From the simulation with paint, energies $E_{P \text { Lext }}=\int_{0}^{t} s_{P \text { Lext }}(t) d t$ and $E_{P \text { Lext }}^{e q}=\int_{0}^{t} s_{P \text { Lext }}^{e q}(t) d t$ are calculated. The associated differences $\Delta E_{W P}=E_{W P}-E_{F E M}, \Delta E_{P \text { Lext }}=E_{P \text { Lext }}-$ $E_{F E M}, \Delta E_{P L e x t}^{e q}=E_{P L e x t}^{e q}-E_{F E M}$ are finally calculated.

\subsubsection{Case 1 results}

Temperatures $T_{W P}, T_{P \text { Lext }}$ and $T_{P \text { Lint }}$ computed by the FEM model, for the two geometries of Fig. 2.a and 2.b are plotted in Fig. 5.a. The material cools well from $T_{\text {ini }}=100^{\circ} \mathrm{C}$ to $T_{0}=20^{\circ} \mathrm{C}$. The exothermic input heat source leads to a temperature bump. The temperature difference between the external surface $\Delta T$ and between the internal and external surface of the paint $\Delta T_{P L}$ are plotted in Fig. 5.b. The temperature of the external surface of the sample covered with paint is higher than that without paint $(\Delta T<0)$ and the maximum difference is $|\Delta T| \approx 2.8^{\circ} \mathrm{C}$. As expected, the paint isolates the sample from the exterior $\left(T_{P \text { Lext }}<T_{P \text { Lint }}\right)$. The maximum difference $\left|\Delta T_{P L}\right|$ is $0.5^{\circ} C$. The temperature differences $\Delta T$ and $\Delta T_{P L}$ are very high in comparison to the thermal resolution of the infrared camera $\left( \pm 0.02^{\circ} \mathrm{C}\right)$.

The temporal evolutions of the estimated heat sources $s_{F E M}, s_{W P}, s_{P L e x t}$ and $s_{P L e x t}^{e q}$ are plotted in Fig. 5.c and differences $\Delta s_{W P}, \Delta s_{P \text { Lext }}$ and $\Delta s_{P L e x t}^{e q}$ in Fig. 5.d. Without paint, the estimated heat sources are close to those imposed in the FEM model. Due to the filtering process, the maximum error is observed when heat sources quickly change 
over time. With paint, the sandwich plate estimation model is better than the homogeneous plate model $\left(\Delta s_{P \text { Lext }}>\Delta s_{P \text { Lext }}^{e q}\right)$, especially when the imposed heat sources are zero. With the sandwich plate model, the estimated heat sources are also equal to those calculated without paint.

The energies $E_{F E M}, E_{W P}, E_{P L e x t}$ and $E_{P L e x t}^{e q}$ are plotted in Fig. 5.e. The associated relative errors $\Delta E_{W P}, \Delta E_{P L e x t}$ and $\Delta E_{P L e x t}^{e q}$ are plotted as a function of $E_{F E M}$ in Fig. 5.f. Without paint, the energy $E_{W P}$ is slightly lower than $E_{F E M}$. With paint, the energy $E_{P L e x t}$ is overestimated when the homogeneous plate model (eq. (7)) is used. However, with the sandwich plate model (eq. (10)), the energy $E_{P L e x t}^{e q}$ is almost equal to $E_{W P}$, with a slight underestimation with regard to the imposed energy $E_{F E M}$. With the two models considered (equations (7) and (10)), the maximum energy error is obtained during the plateau, when heat sources are null. This could be explained by the fact that, as seen in Figs. 5.c and 5.d, (for time $>25 \mathrm{~s}$ ) and when neglecting the paint, $s_{\text {PLext }}$ are positive whereas $s_{P \text { Lext }}^{e q}$ are negative when the paint is taken into account. The error is lower during the energy increase than during the plateau. Errors in the middle of the energy increase $\left(E_{F E M}=7.10^{7} J^{-3}\right.$, squares in Fig. 5.f $)$, at the beginning of the plateau (crosses in Fig. 5.f) and at the end of it (circles in Fig. 5.f) as shown in Table 2. First, in all the considered instants and for all the models, the error is less than $10 \%$. Then, without paint, the homogeneous plate model exhibits good accuracy with an error always under $6 \%$. With paint, the energy error is considerably reduced when using the sandwich plate model, especially at the end of the experiment, with an error reduction ranging from $10 \%$ with the homogeneous plate model to $5 \%$ with the sandwich plate model.

\subsubsection{Case 2 results}

Temperatures $T_{W P}, T_{P \text { Lext }}$ and $T_{P \text { Lint }}$ computed by the FEM model, for the two geometries of Fig. 2.a and 2.b are plotted in Fig. 6.a. The initial and final temperature 


\begin{tabular}{lcccccc}
\hline$E_{F E M}$ & $\left|\Delta E_{W P}\right|$ & $\frac{\left|\Delta E_{W P}\right|}{E_{F E M}}$ & $\left|\Delta E_{P L e x t}\right|$ & $\frac{\left|\Delta E_{P L e x t}\right|}{E_{F E M}}$ & $\left|\Delta E_{P L e x t}^{e q}\right|$ & $\frac{\left|\Delta E_{P L e x t}^{e q}\right|}{E_{F E M}}$ \\
$\left(J m^{-3}\right)$ & $\left(J m^{-3}\right)$ & $(\%)$ & $\left(J m^{-3}\right)$ & $(\%)$ & $\left(J m^{-3}\right)$ & $(\%)$ \\
\hline $7.10^{7}$ & $4.10^{6}$ & $6 \%$ & $6.10^{6}$ & $9 \%$ & $5.10^{6}$ & $7 \%$ \\
\hline & & & & & \\
$13,5.10^{7}$ (Plateau start) & $4.10^{6}$ & $3 \%$ & $7.10^{6}$ & $5 \%$ & $5.10^{6}$ & $4 \%$ \\
\hline & & & & & \\
$13,5.10^{7}$ (Plateau end) & $8.10^{6}$ & $6 \%$ & $1,3.10^{7}$ & $10 \%$ & $7.10^{6}$ & $5 \%$ \\
\hline
\end{tabular}

of the external surface of the sample are equal to $T_{i n i}=T_{0}=20^{\circ} \mathrm{C}$. The maximal temperature increase due to the exothermic input source is about $17^{\circ} \mathrm{C}$. When the heat sources decrease or are close to zero, the sample cools naturally. Temperature differences $\Delta T$ and $\Delta T_{P L}$ are plotted in Fig. 6.b. The temperature of the external surface of the paint coated sample is lower than that without paint $(\Delta T>0)$ during the heating phase, while the opposite occurs during the cooling phase $(\Delta T<0)$. The maximum difference is $|\Delta T| \approx 1^{\circ} C$. Once again, the paint isolates the sample from the exterior. The maximum difference of $\left|\Delta T_{P L}\right|$ is $0.2^{\circ} C$. The temperature differences $\Delta T$ and $\Delta T_{P L}$ are greater than the thermal resolution of the infrared camera.

The temporal evolutions of the estimated heat sources $s_{F E M}, s_{W P}, s_{P L e x t}$ and $s_{P \text { Lext }}^{e q}$ are plotted in Fig. 6.c and the differences $\Delta s_{W P}, \Delta s_{P L e x t}$ and $\Delta s_{P L e x t}^{e q}$ in Fig. 6.d. Without paint, the estimated heat sources are close to the ones imposed in the FEM model. Once again, quick variations in the heat sources are smoothed by the filtering process. With paint, the homogeneous plate model underestimates the heat source, especially close to the maximum of the imposed heat source. However, the heat sources estimated using the sandwich plate model (equation (10)) are identical to the ones estimated without paint $\left(e_{W P}=e_{\text {Plext }}^{e q}\right)$. 
The energies $E_{F E M}, E_{W P}, E_{P L e x t}$ and $E_{P L e x t}^{e q}$ are plotted in Fig. 6.e. The associated relative errors $\Delta E_{W P}, \Delta E_{P L e x t}$ and $\Delta E_{P \text { Lext }}^{e q}$ are plotted as a function of $E_{F E M}$ in Fig. 6.f. Without paint, the calculated energy $E_{W P}$ is almost equal to the reference $E_{W P} \approx E_{F E M}$, with less than $2 \%$ error. With paint, the energy $E_{P L e x t}$ is underestimated when the homogeneous plate model is used. However, with the sandwich plate model, it becomes $E_{P \text { Lext }}^{e q}=E_{W P} \approx E_{F E M}$. The error is higher during the energy increase than during the plateau. Errors in the middle of the energy increase $\left(E_{F E M}=4.10^{7} \mathrm{~J} \mathrm{~m}^{-3}\right.$, squares in Fig. 6.f) at the beginning of the plateau (crosses in Fig. 6.f) and at the end of it (circles in Fig. 6.f) are given in Table 3. In all the considered instants and for all the models, the error is less than $8 \%$. Without paint, the homogeneous plate model exhibits good accuracy with an error always under $2 \%$. With paint, the energy error is considerably reduced using the sandwich plate model, especially during the energy increase with the error reduction ranging from $8 \%$ with the homogeneous plate model to $0.5 \%$ with the sandwich plate model when $E_{F E M}=7 \%$. During the plateau, the error is almost null with the sandwich plate model.

Table 3. Energy estimation errors.

\begin{tabular}{|c|c|c|c|c|c|c|}
\hline $\begin{array}{l}E_{F E M} \\
\left(J m^{-3}\right)\end{array}$ & $\begin{array}{l}\left|\Delta E_{W P}\right| \\
\left(J m^{-3}\right)\end{array}$ & $\begin{array}{l}\frac{\left|\Delta E_{W P}\right|}{E_{F E M}} \\
(\%)\end{array}$ & $\begin{array}{c}\left|\Delta E_{P \text { Lext }}\right| \\
\left(\begin{array}{l}J m^{-3}\end{array}\right)\end{array}$ & $\begin{array}{c}\frac{\left|\Delta E_{P L e x t}\right|}{E_{F E M}} \\
(\%)\end{array}$ & $\begin{array}{c}\left|\Delta E_{P \text { Lext }}^{e q}\right| \\
\left(J m^{-3}\right)\end{array}$ & $\begin{array}{c}\frac{\left|\Delta E_{P L e x t}^{e q}\right|}{E_{F E M}} \\
(\%)\end{array}$ \\
\hline $4.10^{7}$ & $2.10^{5}$ & $0,5 \%$ & $3,2.10^{6}$ & $8 \%$ & $2.10^{5}$ & $0,5 \%$ \\
\hline $8.10^{7}$ (Plateau start) & $1,7.10^{6}$ & $2 \%$ & $2,3.10^{6}$ & $3 \%$ & $1,0.10^{6}$ & $1 \%$ \\
\hline $8.10^{7}$ (Plateau end) & 0 & 0 & 0 & 0 & 0 & 0 \\
\hline
\end{tabular}




\section{General discussion}

In the previous section, the homogeneous plate model (equation (7)) was validated in the two studied cases without paint. With paint, it was observed that the energy estimation accuracy of this model was lower than that of the sandwich plate model (equation 10) in the two studied cases.

The temperature homogeneity in the material thickness is one of the main hypotheses adopted to formulate the models. Thus, the difference of temperature between the center of the material $(c)$, denoted $T_{c}$ (see Fig. 2), and the outer surface of the sample previously denoted $T_{W P}$ and $T_{P \text { Lext }}$ without and with paint, respectively, are plotted in Fig. 7.a and 7.b for the first case, and in Fig. 8.a and 8.b for the second case.

Without paint, the maximum difference is $\sim 0.025^{\circ} \mathrm{C}$ and $\sim 0.005^{\circ} \mathrm{C}$ in the first and second case, respectively. This difference is equal or smaller to the thermal resolution of classical infrared cameras. In this case, the temperature can be considered homogeneous in the thickness direction, and the homogeneous plate model (equation (7)) allows good estimation of the heat sources, as previously observed.

With paint, the maximum of temperature difference is $\sim 0.6^{\circ} \mathrm{C}$ and $\sim 0.13^{\circ} \mathrm{C}$ in the first and second case, respectively. Temperature in the material is thus not homogeneous in the thickness direction. This could explain why the homogeneous model (equation (7)), that does not take the plate heterogeneity into account, is less accurate than the sandwich model (equation (10)).

\section{Conclusion}

In this paper, a numerical benchmark is used to investigate the impact of a paint layer on the temperature response of a sample and the importance of taking the paint layer into account for heat sources estimation. It appears that the high emissivity paint used 
isolates the sample from the external environment, so the temperature measured at the surface is not the temperature of the central material.

For that study, a sample composed of a central material covered with two paint layers was considered. The central material was submitted to internal heat sources. Two homogeneous thermal loadings were chosen.

Case 1 corresponds to natural cooling of the sample with high temperature variations in the sample. From this case it can be concluded that the estimation, obtained without taking the paint layer into account, globally leads to overestimation of the heat sources and energy while the sandwich plate model allows to reduce these errors. The energy estimation error is reduced from $10 \%$ with the homogeneous plate model to $5 \%$ with the sandwich plate model.

In case 2 , the initial temperature is equal to room temperature, so smaller temperature variations are observed in the sample surface. The energy estimation error is about $8 \%$ with the homogeneous plate model, while it is always below $2 \%$ with the sandwich plate model. Thus the sandwich plate model gives better results than the homogeneous plate model.

This study shows that to estimate heat sources and the associated energy, the paint layers have to be taken in account in the two studied cases. This study also highlights the importance of verifying the temperature homogeneity in the thickness direction of the sample as a function of the thermal loading conditions. For thick samples or samples having low thermal conductivity, for example, this hypothesis needs to be verified and the model used checked.

Authors want to highlight that several other sources of error to estimate heat sources can be noted, e.g. the effect of the paint layer thickness heterogeneity, the model sensitivity to the thermophysical properties uncertainties of the core material and of the paint or the effect of the interface quality between the paint and core material. If this 
problem shows the importance of taking into account the paint layer to estimate heat sources, several other sources of error have to be investigated in future work.

\section{Appendix}

This appendix provides the mathematical formulation for the simplified models of an heterogeneous material in the thickness direction.

The hypotheses adopted for these formulations are $e_{1}=e_{3}, k_{1}=k_{3}, \widetilde{T_{1}}=\widetilde{T_{2}}=\widetilde{T}$, $\frac{\partial \widetilde{T_{1}}}{\partial t}=\frac{\partial \widetilde{T_{2}}}{\partial t}=\frac{\partial \widetilde{T}}{\partial t}$, and $\operatorname{lap}\left(\widetilde{T_{1}}\right)=\operatorname{lap}\left(\widetilde{T_{2}}\right)=\operatorname{lap}(\widetilde{T})$. Integration of equation $(1)$ on the thickness sandwich sample leads to:

$$
\frac{1}{e} \int_{-e / 2}^{e / 2} \rho C \frac{\partial T}{\partial t} d z-\frac{1}{e} \int_{-e / 2}^{e / 2} k l a p(T) d z=\frac{1}{e} \int_{-e / 2}^{e / 2} s_{i} d z+\frac{1}{e} \int_{-e / 2}^{e / 2} s_{e} d z
$$

Since the heat sources are equal to zero in the paint layers, the first term of the right hand side of the equation can be written:

$$
\int_{-e / 2}^{e / 2} s_{i} d z=\int_{-e / 2}^{-e_{2} / 2} s_{1} d z+\int_{-e_{2} / 2}^{e_{2} / 2} s_{2} d z+\int_{e_{2} / 2}^{e / 2} s_{3} d z=\int_{-e_{2} / 2}^{e_{2} / 2} s_{2} d z=e_{2} \widetilde{s_{2}}
$$

Then, the first term of the left hand side can be written:

$$
\int_{-e / 2}^{e / 2} \rho C \frac{\partial T}{\partial t} d z=\int_{-e / 2}^{-e_{2} / 2} \rho C \frac{\partial T}{\partial t} d z+\int_{-e_{2} / 2}^{e_{2} / 2} \rho C \frac{\partial T}{\partial t} d z+\int_{e_{2} / 2}^{e / 2} \rho C \frac{\partial T}{\partial t} d z
$$

with :

$$
\int_{-e_{2} / 2}^{e_{2} / 2} \rho C \frac{\partial T}{\partial t} d z=\int_{-e_{2} / 2}^{e_{2} / 2} \rho_{2} C_{2} \frac{\partial T_{2}}{\partial t} d z=e_{2} \rho_{2} C_{2} \frac{\partial \widetilde{T_{2}}}{\partial t}
$$

where $\widetilde{T_{2}}$ is the averaged temperature in the material 2 . Then, with an appropriate variable change:

$$
\int_{-e / 2}^{-e_{2} / 2} \rho C \frac{\partial T}{\partial t} d z=\int_{-e_{1} / 2}^{e_{1} / 2} \rho_{1} C_{1} \frac{\partial T_{1}}{\partial t} d z=\rho_{1} C_{1} e_{1} \frac{\partial \widetilde{T_{1}}}{\partial t}
$$

This last formulation is applied to the third term of equation (14). Then, an identical 
formulation as used for equation (14) with the Laplacian term, and the second term can be written:

$$
\begin{array}{r}
\int_{-e_{2} / 2}^{e_{2} / 2}-k l a p(T) d z=-k_{2} \int_{-e_{2} / 2}^{e_{2} / 2}\left(\frac{\partial^{2} T}{\partial x^{2}}+\frac{\partial^{2} T}{\partial y^{2}}+\frac{\partial^{2} T}{\partial z^{2}}\right) d z \\
=-k_{2}\left[\frac{\partial^{2}}{\partial x^{2}} \int_{-e_{2} / 2}^{e_{2} / 2} T d z+\frac{\partial^{2}}{\partial y^{2}} \int_{-e_{2} / 2}^{e_{2} / 2} T d z\right]-k_{2}\left[\frac{\partial T}{\partial z}\right]_{-e_{2} / 2}^{e_{2} / 2} \\
=-k_{2} e_{2} \operatorname{lap}_{2 D} \widetilde{T_{2}}-k_{2}\left[\frac{\partial T_{2}}{\partial z}\right]_{-e_{2} / 2}^{e_{2} / 2}
\end{array}
$$

Identical formulations are used for the first and third terms, leading to the following equation:

$$
\begin{array}{r}
\int_{-e / 2}^{e / 2}-k l a p(T) d z=-k_{1} e_{1} l a p_{2 D} \widetilde{T_{1}}-k_{3} e_{3} l a p_{2 D} \widetilde{T_{3}}-k_{2} e_{2} l a p_{2 D} \widetilde{T_{2}} \\
-k_{1}\left[\frac{\partial T_{1}}{\partial z}\left(-e_{2} / 2\right)\right]-k_{1}\left[\frac{\partial T_{1}}{\partial z}(-e / 2)\right] \\
-k_{2}\left[\frac{\partial T_{2}}{\partial z}\left(e_{2} / 2\right)\right]-k_{2}\left[\frac{\partial T_{2}}{\partial z}\left(-e_{2} / 2\right)\right] \\
-k_{3}\left[\frac{\partial T_{3}}{\partial z}(e / 2)\right]-k_{3}\left[\frac{\partial T_{3}}{\partial z}\left(e_{2} / 2\right)\right] \\
=\left(-2 k_{1} e_{1}-k_{2} e_{2}\right) \operatorname{lap}_{2 D}(\widetilde{T})+k_{1}\left(\frac{\partial T_{1}}{\partial z}(-e / 2)-\frac{\partial T_{3}}{\partial z}(e / 2)\right) .
\end{array}
$$

The conservation of flux through the sample surfaces in $\pm e_{2} / 2$ leads to:

$$
k_{1} \frac{\partial T_{1}}{\partial z}\left(-e_{2} / 2\right)=k_{2} \frac{\partial T_{2}}{\partial z}\left(-e_{2} / 2\right), \text { and } k_{2} \frac{\partial T_{2}}{\partial z}\left(e_{2} / 2\right)=k_{3} \frac{\partial T_{3}}{\partial z}\left(e_{2} / 2\right)
$$

This leads to the following equation:

$$
\int_{-e / 2}^{e / 2}-k \operatorname{lap}(T) d z=\left(-2 k_{1} e_{1}-k_{2} e_{2}\right) \operatorname{lap}_{2 D} \widetilde{T}+k_{1}\left(\frac{\partial T_{1}}{\partial z}(-e / 2)-\frac{\partial T_{3}}{\partial z}(e / 2)\right)
$$

Considering the conservation of flux on the two samples surfaces in $\pm e / 2$, the last term of the previous equation is:

$$
k_{1}\left(\frac{\partial T_{1}}{\partial z}(-e / 2)-\frac{\partial T_{3}}{\partial z}(e / 2)\right)=2\left(\epsilon \sigma \widetilde{T}^{4}+h\left(\widetilde{T}-\widetilde{T}_{0}\right)\right)
$$


It is now possible to write equation 12 in the following form:

$\frac{2 e_{1} \rho_{1} C_{1}+e_{2} \rho_{2} C_{2}}{e} \frac{\partial \widetilde{T}}{\partial t}-\frac{2 e_{1} k_{1}+e_{2} k_{2}}{e} \operatorname{lap}_{2 D}(\widetilde{T})+\frac{2}{e}\left(\sigma \widetilde{T^{4}}+h\left(\widetilde{T}-T_{0}\right)\right)=\frac{e_{2}}{e} \widetilde{s_{2}}+\widetilde{s_{e}}$

Considering the previous equation at initial time leads to:

$$
\widetilde{s_{e}}=\frac{2}{e}\left[\sigma \epsilon T_{0}^{4}\right]
$$

Thus, it is possible to formulate the complete $2 \mathrm{D}$ model:

$\left.\frac{2 e_{1} \rho_{1} C_{1}+e_{2} \rho_{2} C_{2}}{e_{2}} \frac{\partial \widetilde{T}}{\partial t}-\frac{2 e_{1} k_{1}+e_{2} k_{2}}{e_{2}} \operatorname{lap}_{2 D}(\widetilde{T})+\frac{2 \epsilon \sigma}{e_{2}}\left(\widetilde{T^{4}}-T_{0}^{4}\right)+\frac{2 h}{e_{2}}\left(\widetilde{T}-T_{0}\right)\right)=\widetilde{s_{2}}=\rho_{2} \widetilde{\dot{q}_{2}}$.

Then, integration of this equation in the transverse direction leads to the $1 \mathrm{D}$ model:

$\left.\frac{2 e_{1} \rho_{1} C_{1}+e_{2} \rho_{2} C_{2}}{e_{2}} \frac{\partial \widetilde{\widetilde{T}}}{\partial t}-\frac{2 e_{1} k_{1}+e_{2} k_{2}}{e_{2}} l a p_{1 D}(\widetilde{\widetilde{T}})+\frac{2 \epsilon \sigma}{e_{2}}\left(\widetilde{\widetilde{T^{4}}}-T_{0}^{4}\right)+2 h\left(\frac{1}{e_{2}}+\frac{1}{l}\right)\left(\widetilde{\widetilde{T}}-T_{0}\right)\right)=\widetilde{\widetilde{s_{2}}}=\rho_{2} \widetilde{\widetilde{q_{2}}}$

and integration in the axial direction leads to the homogeneous model:

$$
\left.\frac{2 e_{1} \rho_{1} C_{1}+e_{2} \rho_{2} C_{2}}{e_{2}} \frac{\partial \widetilde{\widetilde{T}}}{\partial t}+\frac{2 \epsilon \sigma}{e_{2}}\left(\underset{\widetilde{T^{4}}}{\approx}-T_{0}^{4}\right)+2 h\left(\frac{1}{e_{2}}+\frac{1}{l}+\frac{1}{L}\right)\left(\widetilde{\widetilde{T}}-T_{0}\right)\right)=\underset{\widetilde{s_{2}}}{\approx}=\rho_{2} \underset{\widetilde{q_{2}}}{ } .
$$

in which the terms $\frac{1}{e_{2}}+\frac{1}{l} \approx \frac{1}{e_{2}}$ and $\frac{1}{e_{2}}+\frac{1}{l}+\frac{1}{L} \approx \frac{1}{e_{2}}$.

\section{References}

[1] Chrysochoos A., Louche H. An infrared image processing to analyse the calorimetric effects accompanying strain localisation. International Journal of Engineering Science, 38:17591788,2000

[2] Le-Niliot C., Lefevre F. A method for multiple steady line heat sources identification in a diffusive system: application to an experimental 2D problem. International Journal of Heat and Mass Transfer, 44:1425 - 1438, 2001. 
[3] Yi Z., Murio D.A. Identification of source terms in 2D IHCP. Computers and Mathematics with Applications, 47:1517-1533, 2004.

[4] Renault N., Andre S., Maillet D., and Cunat C. A two-step regularized inverse solution for 2D heat source reconstruction. International Journal of Thermal Sciences, 47:834-847, 2008.

[5] Louche H., Chrysochoos A. Thermal and dissipative effects accompanying Luders band propagation. Materials Science and Engineering, A307:15-22, 2001.

[6] Louche H., Vacher P., Arrieux R. Thermal observations associated with the Portevin Le Chatelier effect in an AlMg alloy. Materials Science and Engineering A, 404:188-196, 2005.

[7] Boulanger T., Chrysochoos A., Mabru C., Galtier A. Calorimetric analysis of dissipative and thermoelastic effects associated with the fatigue behavior of steels. International Journal of Fatigue, 26:221-229, 2004.

[8] Pastor M.L., Balandraud X., Grediac M., Robert J.L. Applying infrared thermography to study the heating of 2024-T3 aluminium specimens under fatigue loading. Infrared Physics E Technology, 51:505-515, 2008.

[9] Maquin F., Pierron F. Heat dissipation measurements in low stress cyclic loading of metallic materials: From internal friction to micro-plasticity. Mechanics of Materials, 41:928-942, 2009 .

[10] Chrysochoos A., Berthel B., Latourte F., Pagano S., Wattrisse B., Weber B. Local energy approach to steel fatigue. Strain, 44:327-334, 2008.

[11] Saai A., Louche H., Tabourot L., Chang H.J. Experimental and numerical study of the thermo-mechanical behavior of Al bi-crystal in tension using full field measurements and micromechanical modeling. Mechanics of Materials, 42:275-292, 2010.

[12] Dumoulin S., Louche H., Hopperstad O.S., Brvik T. Heat sources, energy storage and dissipation in high-strength steels: Experiments and modelling. European Journal of Mechanics A/Solids, 29:461-474, 2010.

[13] Schlosser P., Louche H., Favier D., Orgéas L. Image processing to estimate the heat sources related to phase transformations during tensile tests of NiTi tubes. Strain, 43:260-271, 2007. 
[14] Delpueyo D., Balandraud X., Grédiac M. Applying infrared thermography to analyse martensitic microstructures in a $\mathrm{Cu}-\mathrm{Al}-\mathrm{Be}$ shape memory alloy subjected to a cyclic loading. Materials Science and Engineering A, 528:8249-8258, 2011.

[15] Delobelle V., Favier D., Louche H. Heat estimation from infrared measurement compared to DSC for austenite to $\mathrm{R}$ phase transformation in a NiTi alloy. Journal of Materials Engineering and Performance, 22:1688-1693, 2012.

[16] Poncelet M. Multiaxialité, hétérogénéités intrinsèques et structurales des essais d'auto échauffement et de fatigue à grand nombre de cycles. Phd Thesis, LMT Cachan, 2007.

[17] Legaie D., Pron H., Bissieux C., Blain V. Thermographic application of black coatings on metals. $9^{\text {th }}$ International Conference on quantitaive InfraRed thermography, 1:1-2, 2008.

[18] Legaie D., Pron H., Bissieux C., Estimation de la diffusivité thermique d’ un revêtement par inversion dans 1’ espace de Hankel. Congrs SFT 08, Toulouse, 1:409-414, 2008.

[19] Favier D., Louche H., Schlosser P., Orgéas L., Vacher P., Debove L. Homogeneous and heterogeneous deformation mechanisms in an austenitic polycrystalline Ti-50.8 at.\% thin tune under tension. Investigation via temperature and strain fields measurements. Acta Materialia, 55:5310-5322, 2007.

[20] Delobelle V., Favier D., Louche H., Connesson N. Determination of local thermophysical properties and heat of transition from thermal fields measurement during drop calorimetric experiment. Experimental Mechanics, Accepted March 2014.

[21] Granta. Granta design ces selector software. 20 Trumpington Street, Cambridge UK, 2010.

[22] Louche H., Schlosser P., Favier D., Orgéas L. Heat source processing for localized deformation with non-constant thermal conductivity. Application to superelastic tensile tests of NiTi shape memory alloys. Experimental mechanics, A:1-16, Avril 2012.

[23] Delobelle V. Contributions l'étude thermomécanique des alliages à mémoire de forme NiTi et à la réalisation par soudage de matériaux architecturés NiTi. PhD Thesis, Grenoble University, 2012. 


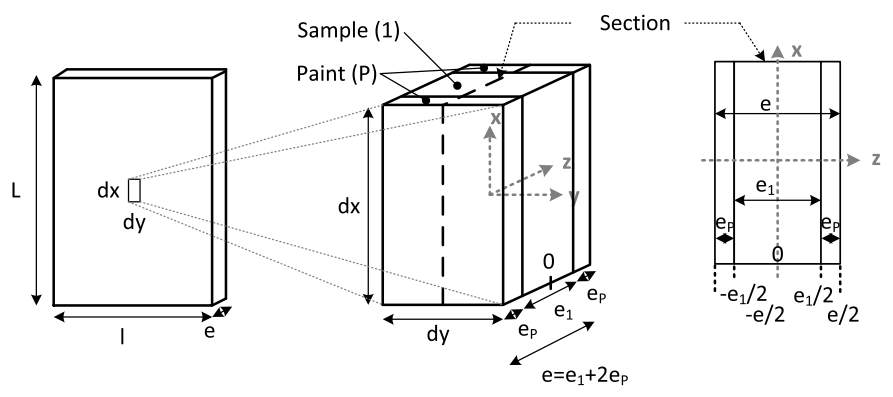

Figure 1. Sandwich plate with the two paint layers of thickness $e_{1}$ and $e_{3}$.
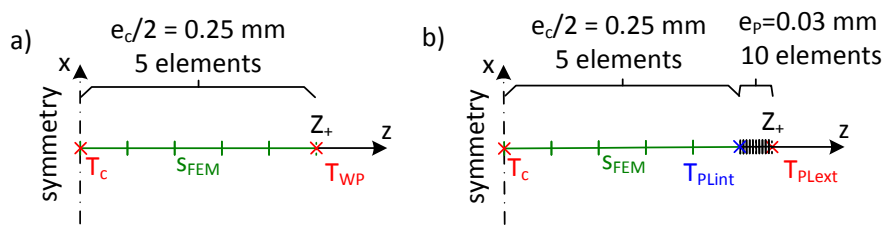

Figure 2. a) FEM model OD without paint layers, b) FEM model 0D with paint layers.
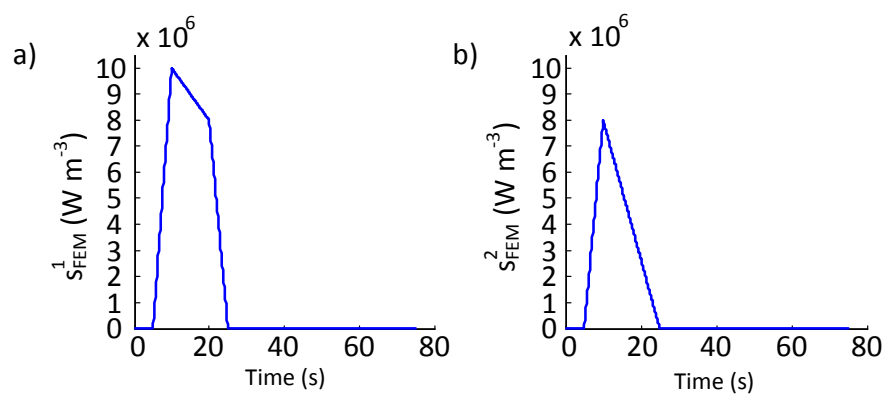

Figure 3. Temporal evolution of the applied heat sources a) in the first case $s_{F E M}^{1}$ and b) in the second case $s_{F E M}^{2}$. 


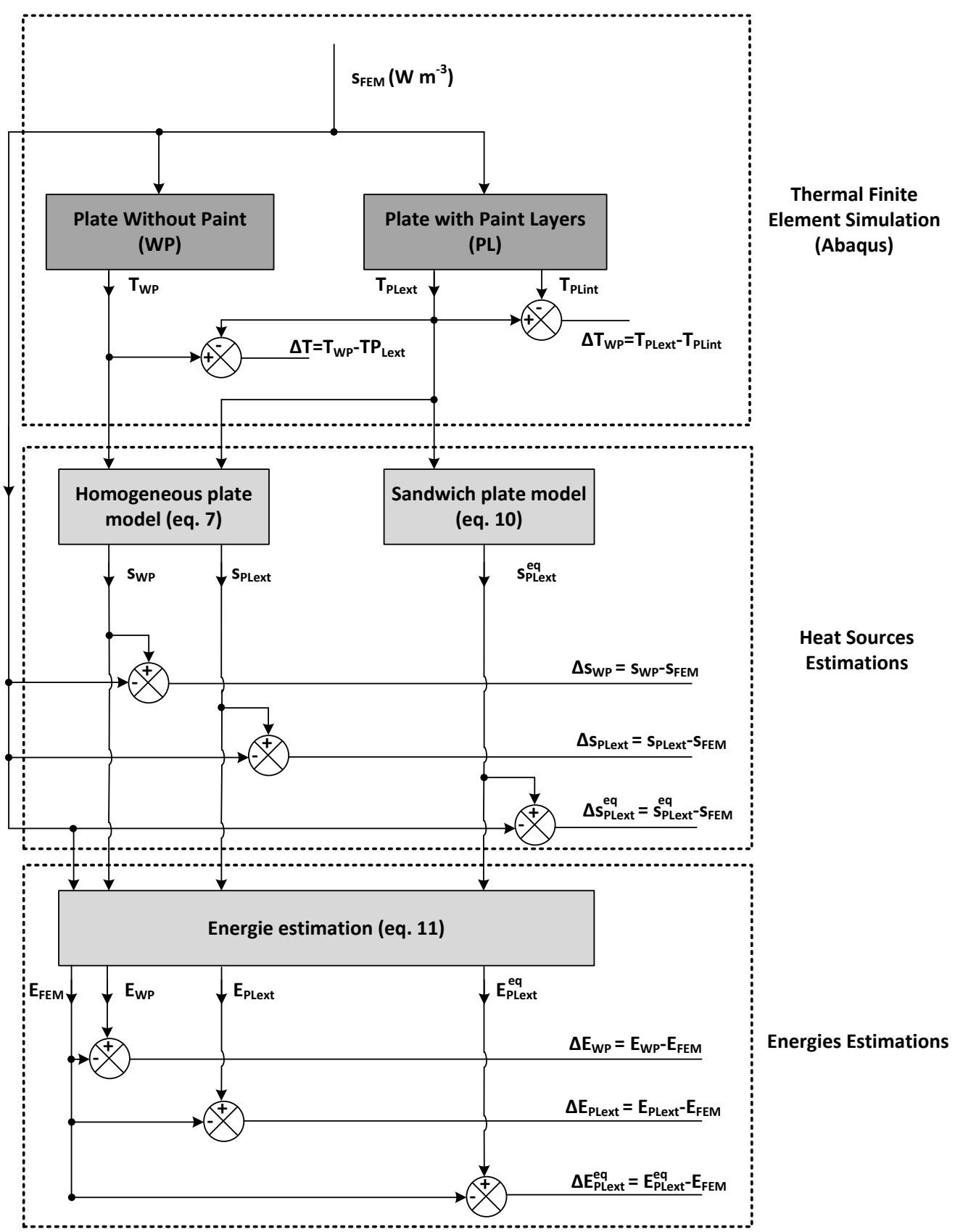

Figure 4. Flowchart of the method proposed to test the influence of the paint layer on heat source estimations. 

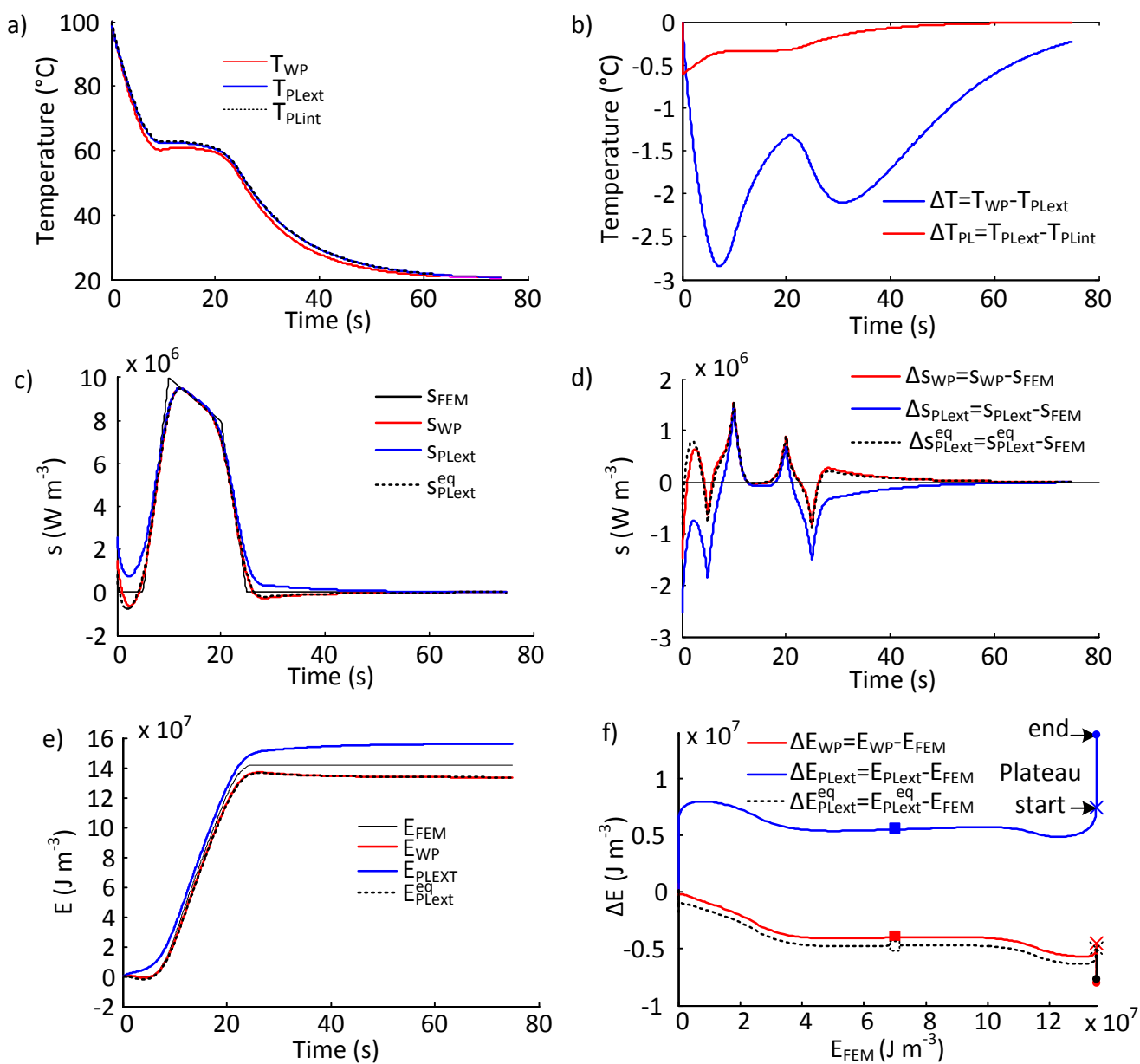

Figure 5. First case (Fig 3.a): a) Temperature variation, b) temperature difference, c) heat source estimation, d) heat source differences, e) energy variationsand f) energy error. 

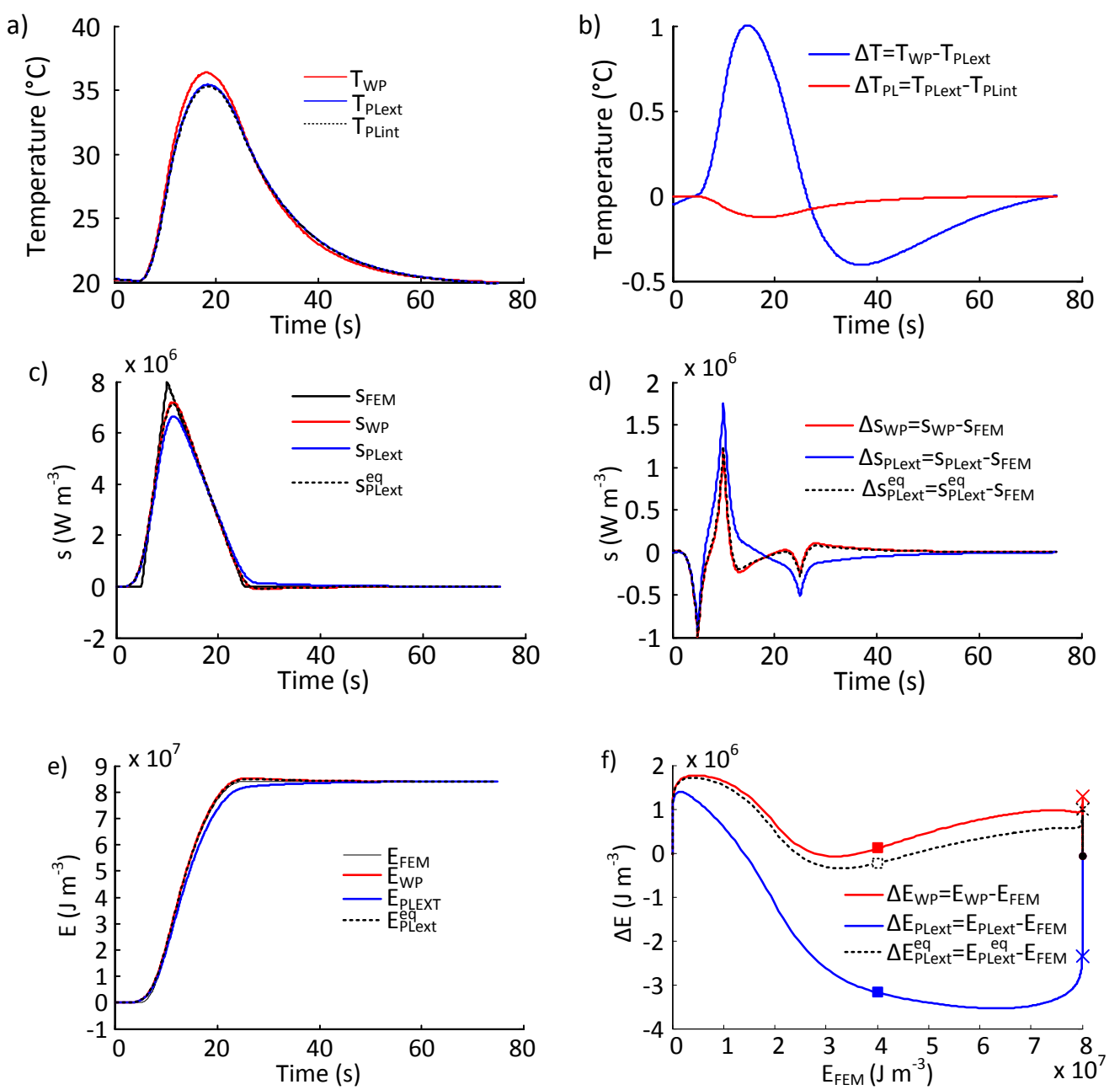

Figure 6. Second case (Fig 3.b): a) Temperature variation, b) temperature difference, c) heat source estimation, d) heat source differences, e) energy variations and f) energy errors.
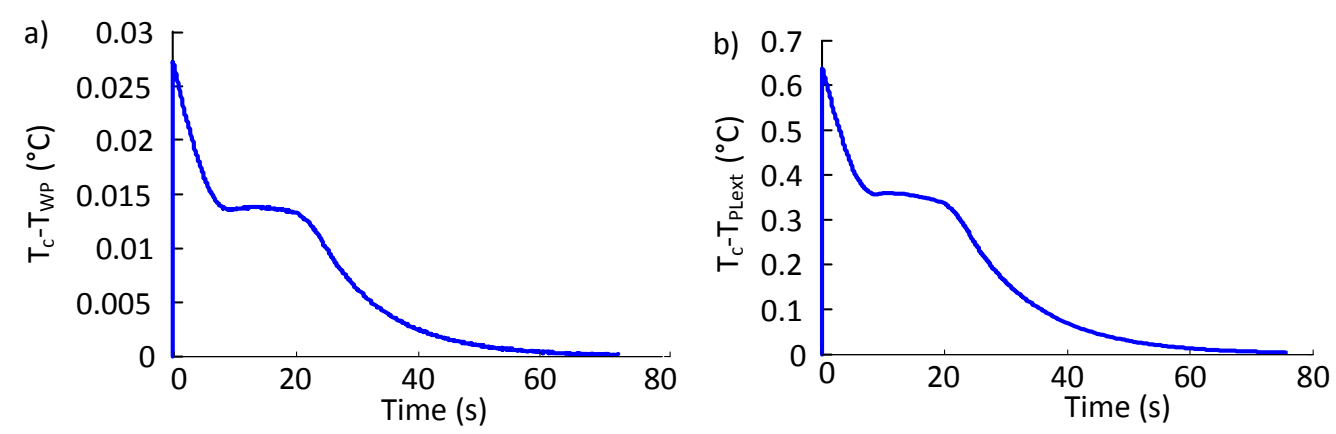

Figure 7. Case 1 loading: difference of temperature between the centre and outer surface of the sample, a) without paint and b) with paint. 

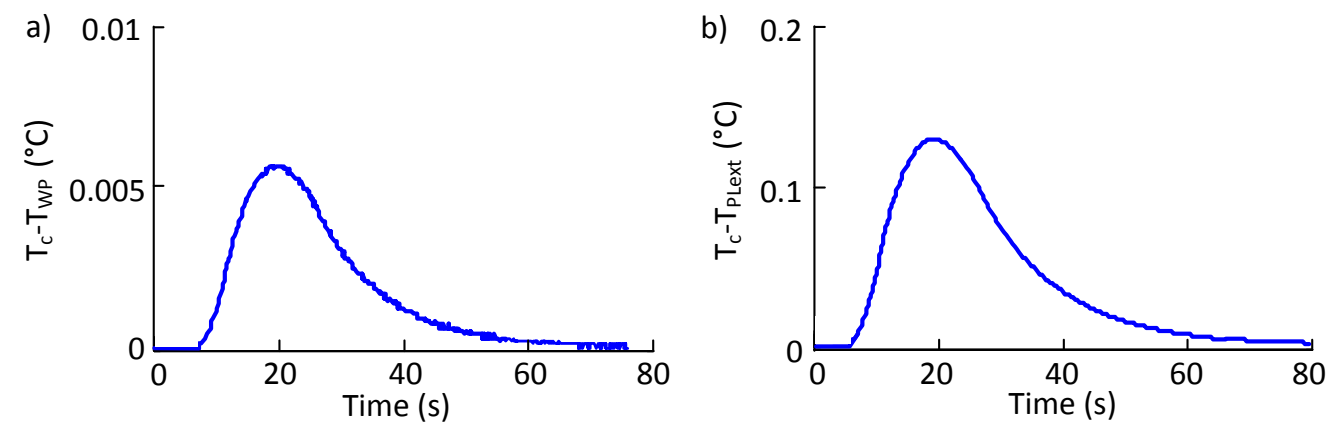

Figure 8. Case 2 loading: difference of temperature between the centre and outer surface of the sample, a) without paint and b) with paint. 